\title{
NATURALEZA JURIDICA DEL CONTRATO DE JOINT VENTURE
}

\section{Reynaldo Pastor Argumedo}

A efectos de iniciar la redacción del presente artículo debemos definir primeramente el concepto del contrato en mención:

"El Joint Venture es un contrato de carácter asociativo, mediante el cual dos o más personas ya sean naturales o jurídicas convienen en explotar un negocio en común por un tiempo determinado, acordando participar en las utilidades resultantes del mismo, así como responder por las pérdidas en forma solidaria e ilimitada".

De la definición expuesta se pueden advertir los elementos del contrato asi como las características del mismo, las cuales detallo a continuación:

a) Pluralidad de sujetos: Este elemento tipificante del contrato es requisito sine qua del mismo, en vista de que para la formación de cualquier acto jurídico, en especial el de los contratos, se requiere la concurrencia de dos o más voluntades, las cuales una vez exteriorizadas a través de la palabra o por medio de actitudes determinan el nacimiento del acto, cuyo fin último será para el caso específico la creación de una figura de carácter asociativo.

b) Affectio Societatis: $\mathrm{Si}$ bien este elemento es propio e inherente de las personas que integran el contrato de sociedad, cuyo efecto directo e indirecto es el otorgamiento de la personería jurídica una vez inscrito el mismo en los Registros Públicos, es a su vez constitutivo del contrato de Joint Venture.

Este elemento es constitutivo del Joint Venture en vista de que los miembros que celebran el contrato, tienen la intención de 
asociarse (1) reuniendo en común capitales y conocimientos a efectos de explotar un negocio determinado por un tiempo limitado.

Los factores constitutivos de la affectio socjetatis para cl presente caso vienen a ser la intencionalidad de asociarse. la explotación de un objeto determinado y el período de tiempo que van a emplear los co-asociados para la prosecución del fin propuesto.

c) Fin de /ucro: Este elemento es a su vez determinante para considerar a la presente figura con carácter asociativo en vista de que las partes al explotar en común un negocio determinado persiguen como fin el generar utilidades derivadas del mismo y distribuirselas posteriormente.

d) Participación en las pérdidas: Este elemento es considerado de gran importancia a efectos de determinar si la figura creada es o no un Joint Venture. La obligación de responder por las pérdidas en forma solidaria e ilimitada, constituye un factor decisivo para distinguir esta figura respecto de las demás.

e) Carácter personal: Comúnmente llamado intuito personae, constituye un elemento imprescindible para la existencia de la figura asociativa en vista de que los co-asociados al gozar de un igual derecho de control, dirección, representación así como responder solidaria e ilimitadamente frente a terceros por las pérdidas que pueda ocasionar el negocio, es necesario que se tome en cuenta las calidades morales e intelectuales de cada uno de ellos. Para el caso de una persona jurídica co-asociada, se analizará la reputación de la misma en la vida mercantil o industrial según sea el caso.

Estos cinco elementos vienen a ser en sintesis los más impor. tantes dentro del contrato de Joint Venture.

(1) El concepto de asociación para el presente artículo es atribuido a la intención de los co-asociados de explotar un negocio común, afectando capitales y/o servicios para la prosecución del fin propuesto. No se le debe confundir con el concepto que le atribuye el Código Civil. 
No obstante lo expuesto, debo ser preciso en señalar que estos elementos no deben confundirse con los requisitos para la validez del acto jurídico. Son dos conceptos totalmente distintos. Mientras los elementos del contrato de Joint Venture se encuentran dentro del mismo una vez exteriorizada la voluntad de los co-asociados, los segundos deben estar presentes para la validez del acto, cuyo efecto inmediato es la formación del mismo.

Habiendo expuesto los elementos del contrato, paso a analizar las características del mismo, las cuales detallo a continuación:

1) Plurilateral: Esta característica es entendida como la concurrencia de varias declaraciones de voluntad. Vienen a constituir un conjunto de manifestaciones de voluntad dirigidas hacia un solo objetivo, el cual es explotar un objeto común y distribuirse las utilidades del mismo, a diferencia de constituir mediante el acuerdo de voluntades, obligaciones contrapuestas como en todo contrato bilateral.

Esta característica es bastante discutible e induce a pensar si el Joint Venture viene a ser un contrato o simplemente un acto colectivo, es decir una pluralidad de voluntades dirigidas en su conjunto a explotar una actividad mercantil determinada y por ende crear una figura asociativa.

No obstante lo expuesto considero personalmente que al Joint Venture se le debe atribuir la calificación de contrato, en vista de que al adolecer de personalidad juridica y por ende no formar un ente distinto al de las personas que lo conforman; dichos miembros se encuentran en una situación conjunta de acreedor y deudor al mismo tiempo. Es decir, al obligarse a afectar un bien a la comunidad de intereses se constituyen en deudor frente a los demás co-asociados hasta no cumplir con la entrega del bien y éstos a su vez en acreedores al exigirle al co-asociado moroso la entrega del mismo. Asimismo al responder un co-asociado por la totalidad de las pérdidas del negocio frente a terceros, se convierte automáticamente por subrogación activa en acreedor de sus demás co-asociados y estos a su vez en deudores de aquel.

Es en base a la argumentación expuesta, por la, cual consi- 
dero al Joint Venture como un contrato y no como un acto colectivo o complejo.

2) Conmutativo: El contrato de Joint Venture posee esta característica en vista de que las prestaciones a cargo de los coasociados son equivalentes. Es decir el carácter equivalente no siempre atribuido al valor económico del bien materia de afectación, sino también atribuido a la obligación de cada co-asociado de afectar un bien, ya sea en dinero o en especie.

3) Tracto Sucesivo: En base a que las obligaciones a cargo de los co-asociados (las cuales se encuentran pactadas en el contrato) se van renovando en el transcurso del tiempo de duración de la explotación del negocio a diferencia de los contratos plurilaterales de ejecución instantánea.

En cuanto al carácter sinalagmático que gozan los contratos en general debo ser preciso en señalar que en el Joint Venture no existe reciprocidad de prestaciones en vista de que la obligación de afectar un bien a la comunidad de intereses si bien sitúa al co-asociado como deudor frente a sus demás co-asociados, los mismos no se obligan frente a aquel con una determinada prestación. El efecto inmediato de la afectación de un bien a la comunidad de intereses es precisamente adoptar la calidad de co-asociado y con ello gozar de los derechos que le atribuye la figura asociativa.

Como conclusión y en base a lo expuesto en los párrafos precedentes debo señalar que el Joint Venture es un contrato asociativo suigéneris.

\section{LA ADMINISTRACION EN EL JOINT VENTURE}

Partiendo de la premisa de que la figura en análisis exige de los sujetos intervinientes en el contrato el carácter personal (intuito personae) a efectos de explotar la realización del fin propuesto, se advierte que el control y dirección del negocio se encuentra a cargo de todos y cada uno de los co-asociados.

Cada co-asociado actúa como principal y representante de los demás frente a los terceros con quienes celebra negocios ju- 
rídicos. Es por ello que los actos que realiza un co-asociado en nombre del Joint Venture obliga a los demás miembros integrantes frente a los terceros.

No obstante existir esta regla general mediante la cual la administración del negocio se encuentra controlada y dirigida por la totalidad de los miembros que conforman el Joint Venture, quepa la posibilidad de celebrar pactos entre los co-asociados a efectos de delegar dicha función en uno o en varios de ellos.

De presentarse esta situación deberá existir un acuerdo escrito mediante el cual las partes manifiesten su voluntad de delegar el mencionado derecho, de lo contrario podría prestarse a una serie de actos dolosos por parte de los co-asociados representantes, del tercero con quien celebran negocios jurídicos o de ambos en su conjunto.

Esta delegación de facultades en uno o varios de loseo-asociados se encuentra fundamentada en el principio del libre albedrio entre las partes. Es precisamente la legislación americana la que fomenta el referido principio.

De otro lado la delegación de facultades de representación, control y dirección a uno o varios co-asociados puede encontrarse cimentada en función del aporte efectuado por dicha persona a la comunidad de intereses (2).

Si bien es cierto que el grado de valorización del bien afectado a la comunidad de intereses no es considerado comúnmente como elemento apreciativo para que se determine un porcentaje en la dirección y control del negocio, cabe señalar que en algunos acuerdos de Joint Venture este constituye un factor primordial. Asimismo el grado de experiencia en el negocio propuesto así como la capacidad empresarial constituyen factores decisivos para que una persona natural o jurídica según la situación que se presente, pueda ser considerada por los demás co-asociados como

(2) Ver Tesis: El Joint Venture y la Asociación en Participación. Reynaldo, Pastor Argumedo Publicada: Setiembre 1982. Biblioteca de la Pontificia Universidad Católica del Perú. Cap. II. 
la encargada de la dirección, representación y control de la empresa (3).

Habiendo expuesto la regla general, así como las diferentes hipótesis de delegación empresarial que se pueden presentar en la práctica mercantil, paso a continuación a desarrollar un breve análisis de las diversas relaciones que se generan entre los co-asociados y el co-asociado representante así como frente a terceros y la responsabilidad que se deriva de las mismas.

A efectos de iniciar la segunda parte del artículo, debo señalar que los co-asociados al poseer como regla general un igual derecho de control, dirección y representación, los actos que celebren en forma individual frente a terceros obligan a sus demás coasociados. Dichos actos deben encontrarse encaminados única y exclusivamente a explotar el fin del negocio. Sin embargo si el co-asociado actor se extralimitó en sus facultades, obligará solamente a sus demás co-asociados, si el tercero con quien celebró el negocio jurídico desconocía la extralimitación de facultades.

A contrario sensu no obligará a los demás co-asociados si el tercero conocía de la extralimitación de facultades, sin embargo ello no constituye un impedimento para que quede obligado única y exclusivamente frente al mismo.

Otra situación que podría presentarse en la práctica mercantil es que el gestor del negocio (4) actúe frente a terceros dolosamente (el dolo atribuido a la inejecución de obligaciones y no en cuanto al nacimiento del acto jurídico), causando en la ejecución del contrato un perjuicio a sus demás co-asociados.

En este caso si bien el gestor no se extralimita en sus facultades, tiene la intención de causar un daño al negocio, ya sea no

(3) El término "empresa" debe considerarse análogo al término negocio. No se le debe atribuir el concepto de persona juridica para la lectura del presente artículo.

(4) Gestor: Co-asociado a quien se le ha delegado las facultades de representación, control y dirección de la empresa. 
cumpliendo con la prestación debida o buscando una ventaja económica personal.

De presentarse esta situación, al poseer la representación del negocio y ser co-asociado, obliga con el mencionado acto a sus demás co-asociados frente al tercero contratante. Pero ello no implica que los co-asociados no le inicien una acción de daños y perjuicios (amparándose en el Art. $1320^{\circ}$ del Código Civil y no en el $1136^{\circ}$ del referido cuerpo de leyes) por mala gestión. Esta situación me induce a reflexionar que dentro del contrato asociativo que genera el nacimiento de la figura del Joint Venture, se encuentra inmerso un contrato de mandato, el cual se manifestará a la luz de los hechos en forma conjunta o separada según sean gestores de la empresa los co-asociados en su totalidad o uno solo.

Otra situación que se puede presentar en la práctica mercantil es que el gestor del negocio no sea propiamente un co-asociado. El Derecho Anglosajón, en especial la legislación norteamcricana, permite que los co-asociados deleguen sus facultades de representación en un no asociado. Esta situación es poco común en la práctica mercantil pero no implica cue no sea objeto de un análisis jurídico el cual detallo a continuación:

(a) $\mathrm{Si}$ el gestor no asociado se extralimita en sus funciones frente a los terceros, no obligará con sus actos a los co-asociados en la medida que dicho gestor sólo posee la calidad de un simple mandatario y no de co-asociado.

Para esta situación especifica se trae a colación el principio jurídico de que "quienes no están autorizados debidamente para ejercer la representación no obligarán con sus actos y contratos a la sociedad, aunque los ejecuten a nombre de ésta y bajo su firma".

(b) La segunda hipótesis consiste de que el gestor no asociado actúe dolosamente en la ejecución de un negocio juridico. En este caso el gestor no asociado obligará a los co-asociados frente a terceros. en base a su mala gestión y no por concepto de extralimitación de facultades. Pero ello no implica que los co-asociados no le inicien una acción de daños y perjuicios por su mala gestión, recuperando con ello el daño económico sufrido. 
Habiendo analizado las situaciones expuestas en los párrafos precedentes, describo la responsabilidad que se genera como consecuencia de las mismas.

(a) En el caso de que los co-asociados queden obligados frente a los terceros, los primeros responderán solidaria e ilimitadamente frente a los últimos.

(b) En el caso de que sea solamente el gestor co-asociado o no asociado el responsable frente a terceros, responderá con su patrimonio personal.

Al haber terminado de escribir el presente artículo quiero hacer partícipe a los lectores de mi especial agradecimiento al Dr. Manuel De la Puente y Lavalle, quien con su apoyo moral e intelectual me condujo por el buen camino del Derecho.

\section{LA DISOLUCION EN EL JOINT VENTURE}

A efectos de iniciar la redacción del presente artículo, debemos formularnos la pregunta siguiente: ¿E1 Joint Venture puede ser objeto de disolución a pesar de no gozar de personalidad jurídica?

La respuesta a la pregunta es compleja, en vista que de acuerdo a nuestro ordenamiento legal (jurídico) no se puede concebir la disolución en contratos asociativos que no gocen de personalidad jurídica, a no ser que la sociedad sea considerada como irregular, en cuyo caso la ley de Sociedades Mercantiles la contempla bajo el título único.

Sin embargo, no obstante lo expuesto en la legislación americana, el Joint Venture es objeto de disolución, en vista de que la figura posee rasgos característicos de la Partnership y ello determina que al finalizar el negocio o incurrir en causales ya sean contempladas en el contrato asociativo o en la Uniform Partnership Act, pueda acogerse a la disolución.

Ahora bien, cabe preguntarnos cuáles son las causales que se presentan en la práctica mercantil americana. 
La primera de ellas se genera como consecuencia del vencimiento del término de duración del negocio que los co-asociados pactaron en el contrato.

La segunda causal viene a ser aquella mediante la cual la explotación del negocio termina e induce a las partes a finalizar el mismo.

La tercera se genera como consecuencia del fallecimiento de uno de los co-asociados y ello determina que al ser indispensable la presencia de dicho miembro para la prosecusión del fin social, origine un acuerdo de disolución.

Sin embargo, si en el contrato se pactó que de producirse el caso en mención, las partes continuarian la explotación del negocio, el Joint Venture seguirá surtiendo efectos.

Asimismo, no obstante no haberse pactado el mencionado acuerdo, los co-asociados sobrevivientes, por decisión unánime, una vez producido el hecho, pueden acordar la explotación del negocio de dos maneras:

a) Con los herederos del causante, o

b) Continuar ellos mismos la explotación del negocio.

La cuarta causal se genera como consecuencia del advenimiento de un impedimento físico por parte de uno de los co-asociados. En esta situación se aplicará la misma regla contemplada para la causal tercera, es decir, se podrá o no continuar con el representante legal del incapaz.

La quinta causal se determina como consecuencia de la quiebra de uno de los co-asociados. En el presente caso, a efectos de salvar el negocio, puede pactarse que el co-asociado quebrado sea ex cluido del mismo y continúe sin la participación de aquel.

La última causal se genera cuando el negocio deviene en contrario al interés social, así como prohibido por ley. En este caso no hay pacto que pueda convalidar la eficacia del negocio, ya que en el supuesto de producirse, se estaría celebrando un nuevo contrato asociativo y no una convalidación del mismo. 
En buena cuenta, estas vendrían a ser las causales que con frecuencia aparecen en la vida diaria de un Joint Venture.

Habiendo expuesto, las causales de disolución, cabe formularnos otra pregunta: ¿cuáles son los efectos que genera la disolución en el Joint Venture?

El efecto inmediato es la terminación del negocio, y ello implica que los co-asociados se vean impedidos en continuar la explotación del mismo. El presente efecto determina que única y exclusivamente se continúe con las obligaciones pendientes del negocio y las dirigidas a la terminación del mismo.

Una vez acordada la disolución del negocio, los co-asociados designarán en la persona de uno de ellos o de un tercero aliquidador. Será el liquidador la persona encargada de hacer efectiva las obligaciones pendientes del negocio, con el único fin de dar por terminado el mismo.

El segundo efecto que genera la disolución, es que la comunidad de intereses sea objeto de división y partición, una vez cumplido con las obligaciones del negocio frente a terceros.

Habiendo terminado de pagar las deudas del negocio, se procederá a la distribución entre los co-asociados de los bienes afectos a la comunidad de intereses para luego repartir entre los mismos las ganancias resultantes de la ex plotaclón de aquel.

Finalizado este proceso, el Joint Venture se extingue. 